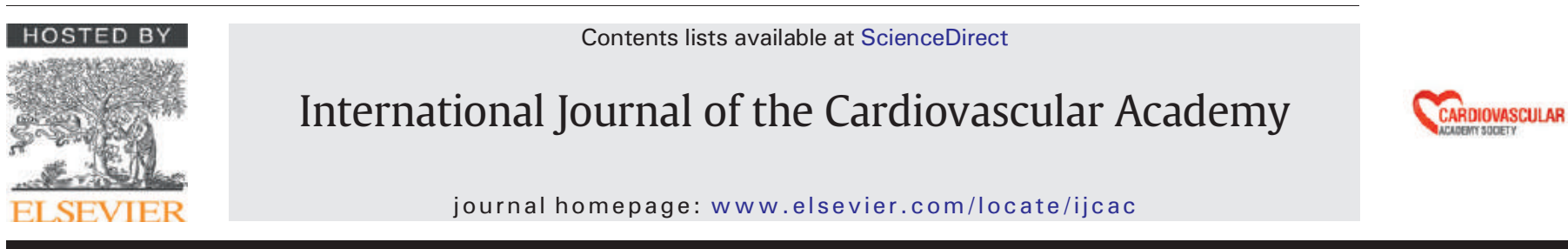

Case report

\title{
Idiopathic epicardial ventricular tachycardia originating from the great cardiac vein
}

\author{
Erkan Yıldırım a ${ }^{\text {a }}$ Barış Buğan ${ }^{\text {b,* }}$, Yalçın Gökoğlan ${ }^{a}$, Murat Çelik ${ }^{\text {a }}$, Uygar Çağdaş Yüksel ${ }^{\text {a }}$, Hasan Kutsi Kabul a \\ a Gulhane Military Medical Academy, Department of Cardiology, Ankara, Turkey \\ b Girne Military Hospital, Cardiology Service, Girne, Turkish Republic of Northern Cyprus
}

\section{A R T I C L E I N F O}

Article history:

Received 12 December 2015

Received in revised form 23 January 2016

Accepted 26 January 2016

Available online 3 March 2016

\section{Keywords:}

Catheter ablation

Great cardiac vein

Ventricular tachycardia

\begin{abstract}
A B S T R A C T
Radiofrequency catheter ablation is accepted as an effective and curative therapy for idiopathic ventricular tachycardia (IVT). Although endocardial radiofrequency (RF) ablation is the common approach for ablation of IVTs, rare patients have been reported in whom ventricular tachycardia (VT) could not be ablated from endocardium due to an epicardial origin of the tachycardia. We, herein, present a case of IVT originating from the great cardiac vein that was successfully ablated within the coronary venous system.

(C) 2016 The Society of Cardiovascular Academy. Production and hosting by Elsevier B.V. All rights reserved. This is an open access article under the CC BY-NC-ND license (http://creativecommons.org/licenses/by-nc-nd/4.0/).
\end{abstract}

\section{Introduction}

Radiofrequency catheter ablation is accepted as an effective and curative therapy for idiopathic ventricular tachycardia (IVT). Although endocardial radiofrequency (RF) ablation is the common approach for ablation of IVTs, rare patients have been reported in whom ventricular tachycardia (VT) could not be ablated from endocardium due to an epicardial origin of the tachycardia. IVTs originating from the epicardial portion are remote from the left ventricular (LV) endocardium and are not amenable to standard approach via endocardial RF ablation. ${ }^{1-3} \mathrm{Sev}-$ eral recent reports have demonstrated that the left coronary veins are potential routes for mapping and ablating VT originating from an epicardial site. ${ }^{4,5}$ IVT/premature ventricular complexes (PVCs) originating from the great cardiac vein constitute only a small number of cases. We, herein, present a case of IVT arising from the great cardiac vein that was successfully ablated within the coronary venous system.

\section{Case report}

A 25-year-old male first admitted to our hospital with palpitation and atypical chest pain for six months. His physical examination was unremarkable. A 12-lead electrocardiogram (ECG) revealed PVCs with left bundle branch block (LBBB) and inferior axis (Fig. 1A). Echocardiography showed a normal examination with a global ejection

\footnotetext{
is There is no conflict of interest.

* Corresponding author at: Girne Military Hospital, Cardiology Service, 99300 Girne, Turkish Republic of Northern Cyprus. Tel.: +90 54883093 45; fax: +90392 8156367 . E-mail address: bbugan@hotmail.com (B. Buğan).

Peer review under responsibility of The Society of Cardiovascular Academy.
}

fraction of $65 \%$ and no chamber enlargement or valve disease. 24-hour Holter monitorization showed frequent monomorphic PVCs and several times of sustained and nonsustained VTs (Fig. 1B). In the cardiovascular stress test, the frequency of PVCs increased with exercise, and the test was terminated because of a sustained VT in stage 3 (Fig. 2A). The patient underwent electrophysiologic study (EPS) using conventional mapping technique. But no early ventricular activation site was found. Epicardial origin was suspected on ECG that showed inferior axis and LBBB with a pseudo delta wave (PdW), precordial R-wave transition in V3 and tall R wave in the inferior leads. In the mapping of the coronary sinus in EPS, the earliest epicardial activation preceding the onset of the QRS complex by $32 \mathrm{~ms}$ was found in the great cardiac vein (Fig. 2B). Also, pace mapping provided an identical (12/12) match with the clinical PVCs morphology. Coronary angiography showed that the distance from the catheter tip to coronary arteries was enough for RF application (Fig. 3A, 3B). One application of RF energy at this site $\left(55^{\circ} \mathrm{C}, 20 \mathrm{~W}\right.$, temperature control) for $30 \mathrm{~s}$ by Marinr multicurve ablation catheter terminated spontaneous PVCs/VT. No VT or PVCs were inducible after RF at that site by ventricular or atrial stimulation. After the procedure, monitorization in coronary care unit showed normal sinus rhythm (Fig. 3C). The patient was discharged from the hospital without any medication and remained completely asymptomatic during 12 months follow-up.

\section{Discussion}

Idiopathic ventricular tachycardia and PVCs mainly originate from the right ventricular outflow tract (RVOT). However, uncommon sites of origin are seldom encountered. The incidence of an epicardial origin in IVT may be as high as $9 \%{ }^{6}$ There is little data regarding the 


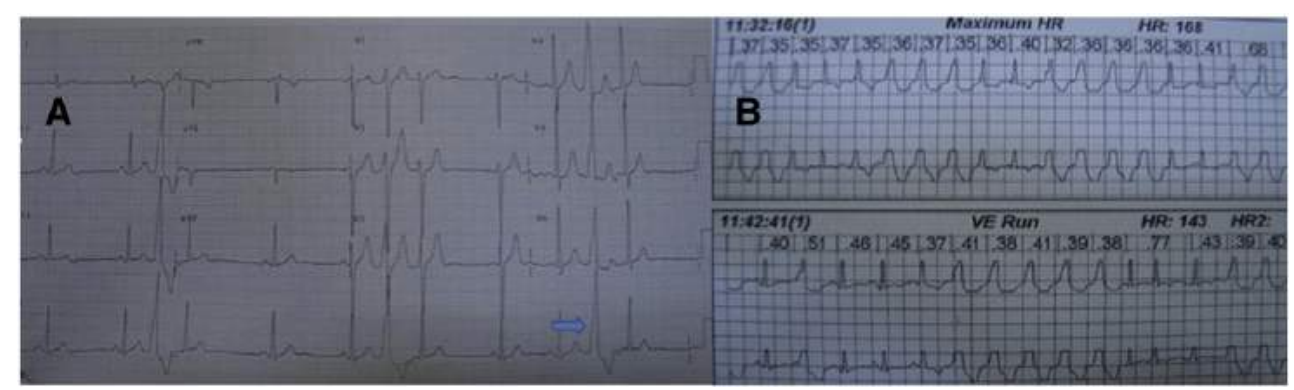

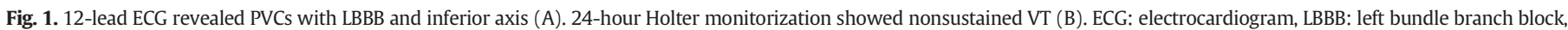
PVCs: premature ventricular complexes, VT: ventricular tachycardia.

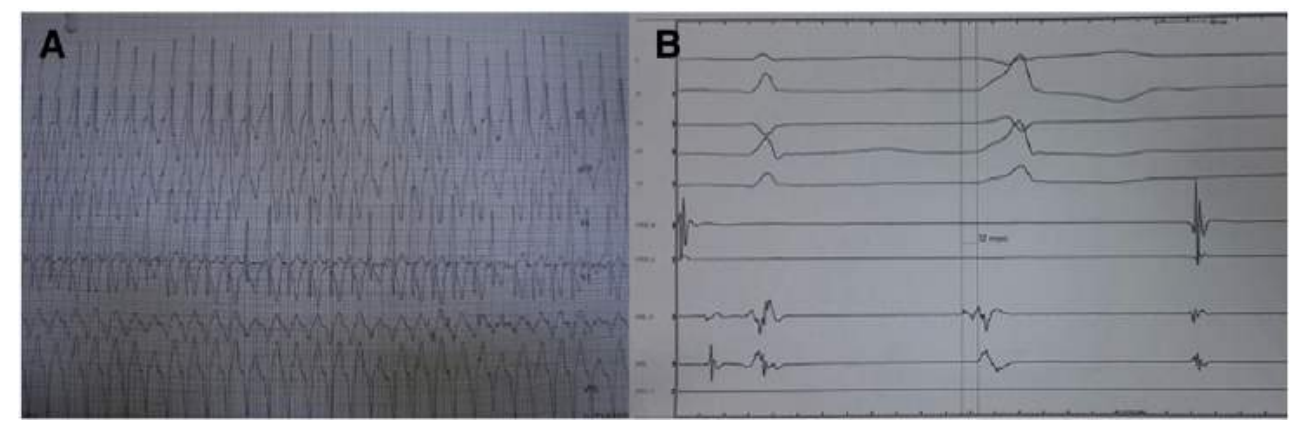

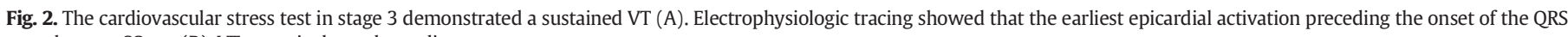
complex was $32 \mathrm{~ms}$ (B). VT: ventricular tachycardia.

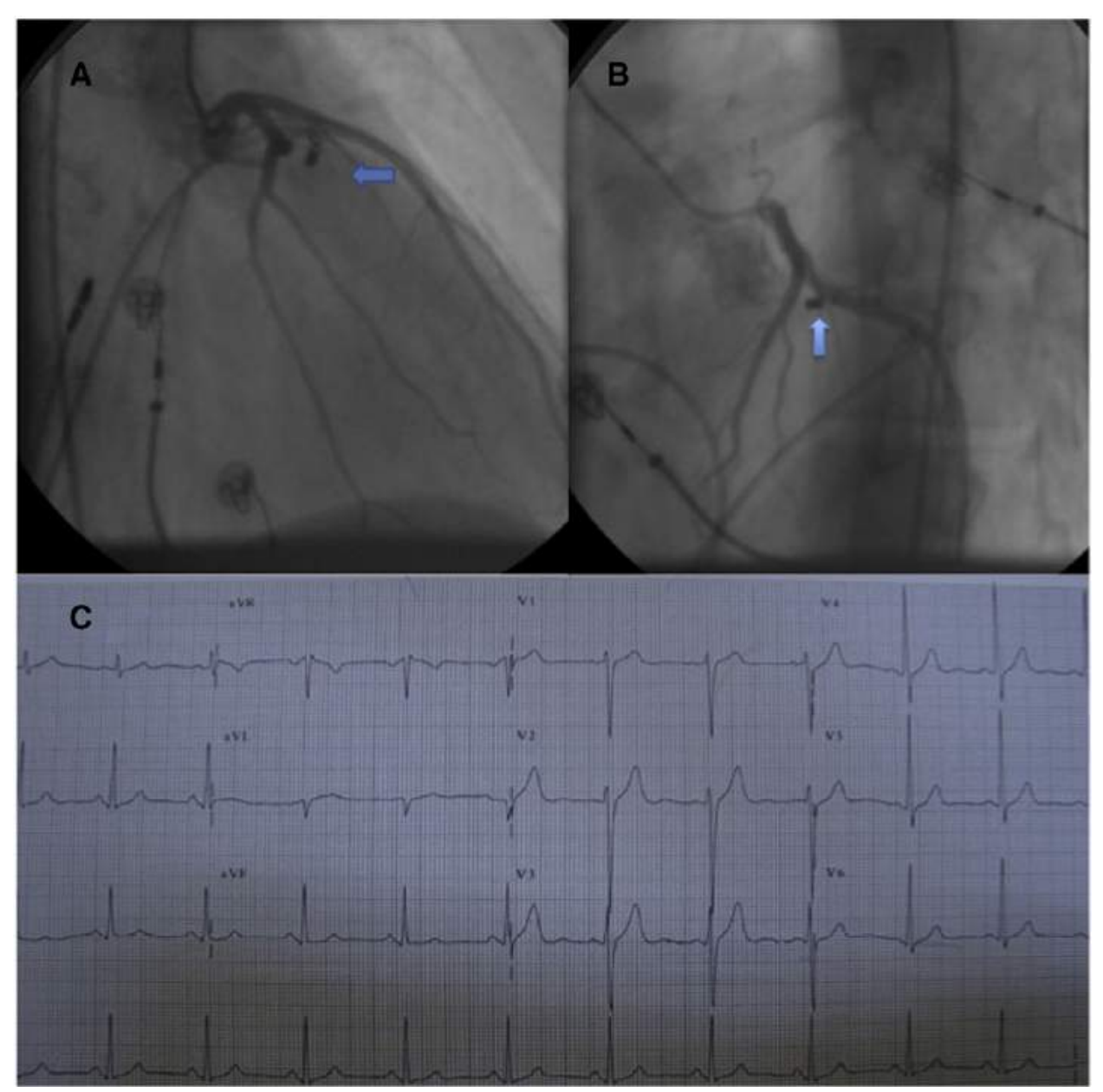

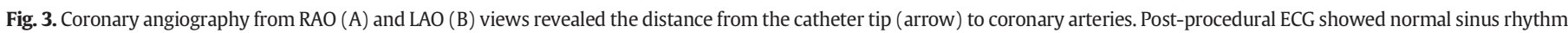
(C). ECG: electrocardiogram, LAO: left anterior oblique, RAO: right anterior oblique. 
prevalence, ECG characteristics, and common sites of tachycardia origin around the coronary sinus and especially its branches. Also, the efficacy of RF catheter ablation of these cases are unclear. ${ }^{6}$ ECG is an essential guide to locate the origin of the tachycardia and to plan the optimal catheter ablation before the patient is brought to the electrophysiology laboratory. An S wave in lead I, deep Q wave in lead aVL, tall R wave in the inferior leads, and precordial transition zone near the leads V1-3 have been reported as the ECG findings of IVTs arising from the LV epicardial portion. ${ }^{7}$ Berruezo et al. ${ }^{8}$ also described the ECG criteria that identified an epicardial origin of VT including PdW $\geq 34 \mathrm{~ms}$ in precordial leads, intrinsicoid deflection time (IDT) $\geq 85 \mathrm{~ms}$ in lead V2, and shortest RS complex duration $\geq 121 \mathrm{~ms}$ in any precordial leads. As is seen in this case, the ECG characteristics have shown almost the same diagnostic criteria related to epicardial origin. Medical therapy and ablation are the options for management of these arrhythmias. Frequency and severity of symptoms play a critical role in determining the treatment strategy. ${ }^{6,7}$ Ablative therapy of epicardial VT/PVCs includes percutaneous and transthoracic epicardial approaches. Several recent reports have demonstrated that the left coronary veins are potential routes for mapping and ablating VT originating from an epicardial site. This procedure can successfully treat the majority of the patients. The transthoracic epicardial approach is recommended in cases in which standard ablation methods have failed. ${ }^{6} \mathrm{RF}$ energy applications within the coronary venous system can be challenging because they can potentially cause complications, such as venostenosis, vein rupture, venous thrombosis, cardiac tamponade, or coronary artery injury, even if they are performed with relatively low power. ${ }^{9}$

\section{Conclusion}

Although idiopathic VT and PVCs mainly originate from the RVOT, uncommon sites of origin are seldom encountered. If the idiopathic
VT/PVCs are not localized in the most common origin, epicardial foci including coronary sinus and its branches should be sought by pacemapping. Also, physicians should keep in mind that a detailed analysis of the ECG is indispensable for diagnosing and ablating IVTs arising from the LV epicardium.

\section{References}

1. Tada H, Nogami A, Naito S, et al. Left ventricular epicardial outflow tract tachycardia: a new distinct subgroup of outflow tract tachycardia. Jpn Circ J 2001;65:723-730.

2. Ito $S$, Tada $H$, Naito $S$, et al. Development and validation of an ECG algorithm for identifying the optimal ablation site for idiopathic ventricular outflow tract tachycardia. J Cardiovasc Electrophysiol 2003;14:1280-1286.

3. Aksu T, Erdem GT, Yalin K. Successful ablation of an epicardial ventricular tachycardia by video-assisted thoracoscopy. Europace 2015;17:1116

4. Obel OA, d'Avila A, Neuzil P, Saad EB, Ruskin JN, Reddy VY. Ablation of left ventricular epicardial outflow tract tachycardia from the distal great cardiac vein. J Am Coll Cardiol 2006;48:1813-1817.

5. Wright M, Hocini M, Ho SY, Haissaguerre M. Epicardial ablation of left ventricular outflow tract tachycardia via the coronary sinus. Heart Rhythm 2009;6:290-291.

6. Daniels D, Lu YY, Morton J, et al. Idiopathic epicardial left ventricular tachycardia originating remote from the sinus of Valsalva: electrophysiological characteristics, catheter ablation, and identification from the 12-lead electrocardiogram. Circulation 2006;113: 1659-1666.

7. Kaseno K, Tada H, Tanaka S, et al. Successful catheter ablation of left ventricular epicardial tachycardia originating from the great cardiac vein. Circ J 2007;71:1983-1988.

8. Berruezo A, Mont L, Nava S, Chueca E, Bartholomay E, Brugada J. Electrocardiographic recognition of the epicardial origin of ventricular tachycardias. Circulation 2004;109: 1842-1847.

9. Giorgberidze I, Saksena S, Krol RB, Mathew P. Efficacy and safety of radiofrequency catheter ablation of left-sided accessory pathways through the coronary sinus. Am J Cardiol 1995;76:359-365. 